\title{
Cauda equina syndrome caused by filum terminale lipoma: magnetic resonance imaging features and surgical treatment
}

\author{
Síndrome de cauda equina causada por lipoma de filum terminale: \\ características do exame de ressonância magnética e do tratamento cirúrgico \\ Benedito Jamilson Araújo Pereira르, Ulysses Caus Batista², Fúlvio Nicolau Bechelli Filho, \\ Carlos Alberto Afonso Ribeiro ${ }^{1}$, Carlos Vanderlei Medeiros de Holanda ${ }^{1}$, Paulo Eduardo Carvalho Galvão ${ }^{1}$
}
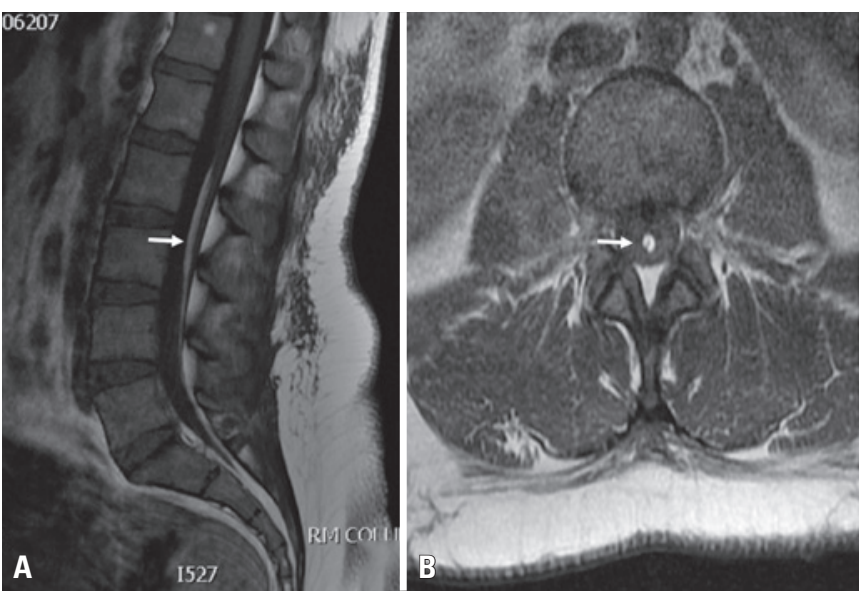

Figure 1. Pre-operative images. T1-weighted magnetic resonance images showing a lipoma of the filum terminale (hyperintense sign within the filum terminale, white arrow) in sagittal (A) and axial (B) planes

A 36-year-old woman with a sudden history of low back pain radiating into the right lower extremity. The physical examination revealed paraparesis, saddle anesthesia and urinary incontinence. Magnetic resonance imaging revealed lipoma of the filum terminale (hyperintense sign within the filum terminale) (Figure 1). The patient underwent surgery without delay with intraoperative neurophysiological monitoring (Figure 2), and she had a full recovery of all neurological deficits.
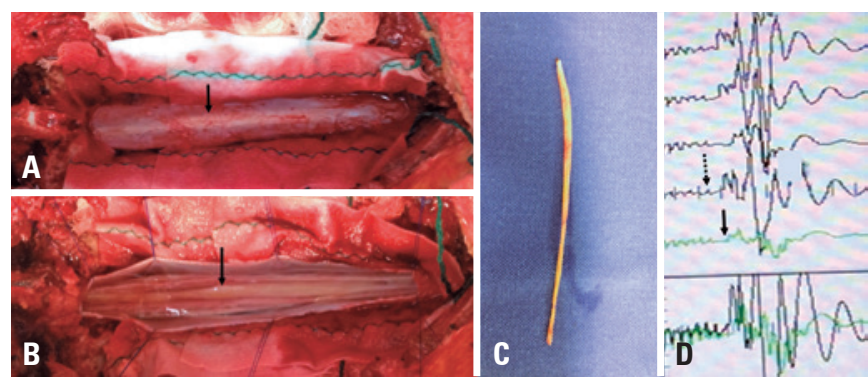

Figure 2. Operative findings surgical features: exposure of the dural sac $(A)$, observe the lipoma of the filum terminale (arrow) and after dural sac open (B). Lipoma filum terminale (C), neurophysiological monitoring (D): tracings demonstrating amplitude of the wave and the number of stages before (continuous arrow) and after (dashed arrow). An increase was observed in amplitude of wave number and phase after resection of the lipoma of the filum terminale

Lipoma of the filum terminale is one of the commonest causes of occult spinal dysraphism. ${ }^{(1)}$ However, only few articles associate lipoma of the filum terminale and neurological deficit. ${ }^{(2)}$

\section{REFERENCES}

1. Finn MA, Walker ML. Spinal lipomas: clinical spectrum, embryology, and treatment. Neurosurg Focus. 2007;23(2):E10. Review.

2. Bulsara KR, Zomorodi AR, Villavicencio AT, Fuchs H, George TM. Clinical outcome differences for lipomyelomeningoceles, intraspinal lipomas, and lipomas of the filum terminale. Neurosurg Rev. 2001;24(4):192-4.

\footnotetext{
' Hospital Beneficência Portuguesa, São Paulo, SP, Brazil.

2 Universidade Estadual de Campinas, Campinas, SP, Brazil.

Corresponding author: Benedito Jamilson Araújo Pereira - Rua Martiano de Carvalho, 669 - Bela Vista - Zip code: 01321 -001 - São Paulo, SP, Brazil - E-mail: benedito.jamilson@ @hotmail.com 